\title{
Recent Knowledge in favor of remdesivir (GS-5734) as a therapeutic option for the COVID-19 infections
}

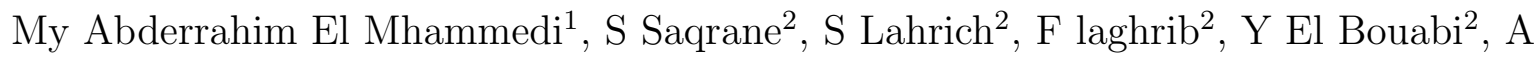 \\ farahi $^{2}$, and $\mathrm{M}$ Bakasse $^{2}$ \\ ${ }^{1}$ Université Sultan Moulay Slimane de Beni-Mellal \\ ${ }^{2}$ University Sultan Moulay Slimane of Beni-Mellal
}

May 20, 2020

\begin{abstract}
The management of SARS-CoV 2 has not yet been clearly determined and is based on the potential therapeutics evaluated during the SARS-CoV and MERS-CoV epidemics. Although there is currently no antiviral treatment for the treatment of human coronavirus infections, the preclinical results with remdesivir (RDV) are promising. This antiviral is identified as a drug option to be evaluated against COVID-19, based on data on its activity in vitro and in vivo on the coronaviruses MERS-CoV and SARS-CoV. Today it is used to fight coronavirus. It acts on COVID-19 by interfering with key stages in the replication cycle of the virus.
\end{abstract}

\section{Hosted file}

Manuscript.doc available at https://authorea.com/users/324447/articles/452635-recentknowledge-in-favor-of-remdesivir-gs-5734-as-a-therapeutic-option-for-the-covid-19infections 